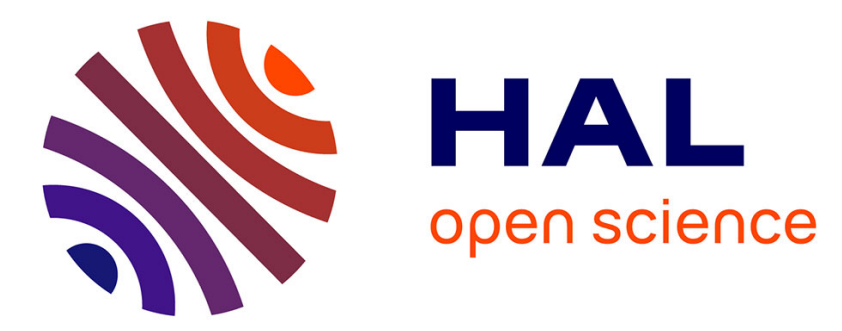

\title{
Dislocation density reduction using overgrowth on hole arrays made in heteroepitaxial diamond substrates
}

\author{
L. Mehmel, R. Issaoui, O. Brinza, A. Tallaire, V. Mille, Julien Delchevalrie, \\ Samuel Saada, Jean-Charles Arnault, F. Bénédic, J. Achard
}

\section{- To cite this version:}

L. Mehmel, R. Issaoui, O. Brinza, A. Tallaire, V. Mille, et al.. Dislocation density reduction using overgrowth on hole arrays made in heteroepitaxial diamond substrates. Applied Physics Letters, 2021, 118 (6), pp.061901. 10.1063/5.0033741 . cea-03141091

\section{HAL Id: cea-03141091 \\ https://hal-cea.archives-ouvertes.fr/cea-03141091}

Submitted on 15 Feb 2021

HAL is a multi-disciplinary open access archive for the deposit and dissemination of scientific research documents, whether they are published or not. The documents may come from teaching and research institutions in France or abroad, or from public or private research centers.
L'archive ouverte pluridisciplinaire HAL, est destinée au dépôt et à la diffusion de documents scientifiques de niveau recherche, publiés ou non, émanant des établissements d'enseignement et de recherche français ou étrangers, des laboratoires publics ou privés. 


\section{Dislocation density reduction using overgrowth on hole arrays made in heteroepitaxial diamond substrates}

Cite as: Appl. Phys. Lett. 118, 061901 (2021); https://doi.org/10.1063/5.0033741

Submitted: 20 October 2020 . Accepted: 28 January 2021 . Published Online: 09 February 2021

(D) L. Mehmel, (D) R. Issaoui, (D) O. Brinza, (D) A. Tallaire, (D) V. Mille, (D) J. Delchevalrie, (D) s. Saada, (D) J. C. Arnault, (iD) F. Bénédic, and (iD) J. Achard

\section{COLLECTIONS}

Paper published as part of the special topic on Ultrawide Bandgap Semiconductors UBS2021
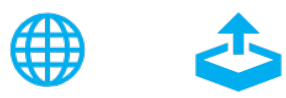

\section{ARTICLES YOU MAY BE INTERESTED IN}

Cross-plane thermal conductivity of GaN/AIN superlattices

Applied Physics Letters 118, 062105 (2021); https://doi.org/10.1063/5.0040811

Dislocation generation mechanisms in heavily boron-doped diamond epilayers

Applied Physics Letters 118, 052108 (2021); https://doi.org/10.1063/5.0031476

High responsivity InGaAsSb p-n photodetector for extended SWIR detection Applied Physics Letters 118, 063503 (2021); https://doi.org/10.1063/5.0037192

Challenge us.

What are your needs for periodic signal detection?

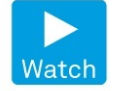

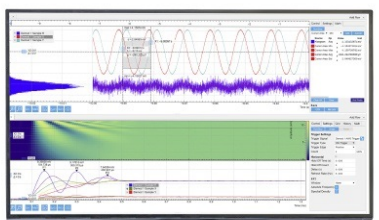

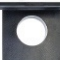

Zurich

- Instruments 


\title{
Dislocation density reduction using overgrowth on hole arrays made in heteroepitaxial diamond substrates
}

Cite as: Appl. Phys. Lett. 118, 061901 (2021); doi: 10.1063/5.0033741

Submitted: 20 October 2020 - Accepted: 28 January 2021 •

Published Online: 9 February 2021

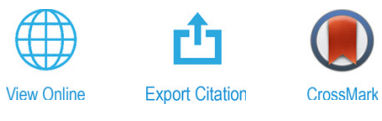

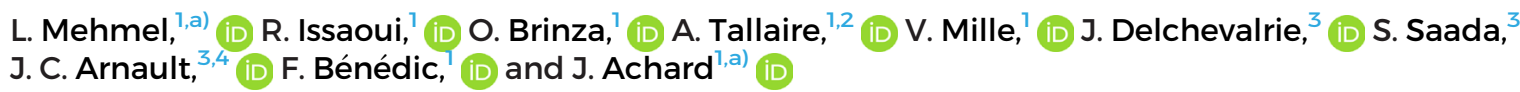

\begin{abstract}
AFFILIATIONS
'LSPM-CNRS, UPR 3407, Université Sorbonne Paris Nord, 99, avenue JB Clément, 93430 Villetaneuse, France

${ }^{2}$ Institut de Recherche de Chimie Paris, Chimie ParisTech, CNRS, PSL Research University, 11 rue Pierre et Marie Curie, 75005 Paris, France

${ }^{3}$ CEA, LIST, Diamond Sensors Laboratory, F-91191 Gif-sur-Yvette, France

${ }^{4}$ NIMBE, UMR CEA-CNRS 3685, Université Paris-Saclay, F-91191 Gif sur Yvette, France
\end{abstract}

Note: This paper is part of the Special Topic on Ultrawide Bandgap Semiconductors.

a) Authors to whom correspondence should be addressed: lahcene.mehmel@lspm.cnrs.fr and jocelyn.achard@lspm.cnrs.fr

\begin{abstract}
The growth of large-area diamond films with low dislocation density is a landmark in the fabrication of diamond-based power electronic devices or high-energy particle detectors. Here, we report the development of a growth strategy based on the use of micrometric laserpierced hole arrays to reduce dislocation densities in heteroepitaxial chemical vapor deposition diamond. We show that, under optimal growth conditions, this strategy leads to a reduction in dislocation density by two orders of magnitude to reach an average value of $6 \times 10^{5} \mathrm{~cm}^{-2}$ in the region where lateral growth occurred, which is equivalent to that typically measured for commercial type Ib single crystal diamonds.
\end{abstract}

Published under license by AIP Publishing. https://doi.org/10.1063/5.0033741

Due to its exceptional chemical/physical properties, such as a wide bandgap energy, high breakdown electric field, high carrier mobility, high thermal conductivity, and low dielectric constant, Chemically Vapor Deposited (CVD) diamond is a promising material for applications in power electronic devices and particle detectors. ${ }^{1-6}$ Nevertheless, the manufacturing of diamond devices is still hampered by the $\mathrm{mm}^{2}$ size and the number of extended defects present in the available single crystal substrates. To overcome these issues, several approaches were recently developed. For example, the growth of a wafer larger than $1 \mathrm{in}$. of single crystal diamond using the mosaic production method was reported. ${ }^{7}$ However, the area close to the junction between the initial substrates remained defective, thus limiting the use of this material in electronic or optical applications. ${ }^{8,9}$ Heteroepitaxial growth of diamond on Ir/MgO (100), ${ }^{10-13} \mathrm{Ir} / \mathrm{YSZ} / \mathrm{Si}$ (001) [Iridium/ Yttria-Stabilized-Zirconia/Silicon(001)], ${ }^{14-17}$ and $\mathrm{Ir} / \mathrm{SrTiO}_{3} / \mathrm{Si}$ $(001)^{18-20}$ substrates was also developed, leading to sizes of up to several inches. However, the crystalline quality lacked significantly behind that obtained for homoepitaxial films because of the difference in the lattice parameter between Ir and diamond (7.2\%). ${ }^{21}$ This indeed led to strain $(-0.68 \mathrm{GPa})^{21}$ and high threading dislocation densities typically in the range of $10^{8}-10^{9} \mathrm{~cm}^{-2}$ for thicknesses of a few hundreds of $\mu \mathrm{m} .{ }^{22,23}$ On the contrary, synthetic commercial type-Ib High Pressure High Temperature (HPHT) diamonds only exhibit densities of $10^{3}-10^{6} \mathrm{~cm}^{-2} \cdot{ }^{24-27}$ Stehl et al. reported a reduction in dislocation densities to $10^{7} \mathrm{~cm}^{-2}$ after 1-mm-thick heteroepitaxial film growth. ${ }^{22}$ Tang et al. used Epitaxial Lateral Overgrowth (ELO) with a gold metal mask designed on a 550-nm-thin (100) heteroepitaxial diamond layer pregrown on a Ir-buffered a-plane sapphire. ${ }^{28,29}$ During growth, the Au stripes filtered and blocked the threading dislocations that normally propagate through the growing diamond film, leading to similar values of dislocation density compared to those after the growth of mm-thick films. Ichikawa et al. demonstrated the fabrication of heteroepitaxial diamond with high crystalline quality using grid patterned nucleation and growth on $\mathrm{Ir}^{30}$ with a dislocation density of $9 \times 10^{6} \mathrm{~cm}^{-2}$.

More recently, Ohmagari et al. developed an original approach taking advantage of tungsten metal impurities incorporation during 
diamond growth performed by hot-filament CVD, which can reach concentrations as high as $10^{18}-10^{19} \mathrm{~cm}^{-3}$. The presence of these metallic impurities induced localized internal stress that interacted with dislocations and strongly influenced their propagation and, thus, their density. ${ }^{31}$ This technique was applied to heteroepitaxial diamond, leading to a reduction in dislocation density although no quantitative value was reported. ${ }^{32} \mathrm{~A}$ high concentration of metallic impurity contamination still necessarily remains though, which is not always acceptable for electronic applications.

Despite those effort and improvements, dislocation density remains fairly high in heteroepitaxial diamond films. Moreover, most of the actual strategies require tedious fabrication steps: growth of $\mathrm{mm}$-thick layers or time-consuming cleanroom processing to produce patterned structures. Even if these techniques are quite well developed and used for the production of single crystal substrates of semiconductor material such as $\mathrm{GaN},{ }^{33-35}$ only a few examples of attempts have been made to apply these strategies to heteroepitaxial diamond.

In this work, a strategy aiming at reducing dislocation density in heteroepitaxial diamond is proposed. It builds on a previous work from our group using a pierced HPHT single crystal substrate, ${ }^{36}$ which led to homoepitaxial CVD diamond films with the dislocation density as low as $10^{3} \mathrm{~cm}^{-2}$. To transfer this concept to heteroepitaxial wafers, a $6 \times 6$ array of $500 \times 500 \mu \mathrm{m}^{2}$ holes was laser-pierced before performing the growth of several hundreds of micrometer-thick CVD diamond to fill up the holes.

Two commercial heteroepitaxial diamond substrates $(10 \times 10$ $\times 0.7 \mathrm{~mm}^{3}$ ) were used (named A1 and A2). They were supplied by the German spin-off company Augsburg Diamond Technology GmbH, and both substrates have lateral and top faces oriented along the $\langle 100\rangle$ directions. They were presumably grown on an Ir/YSZ template by the provider before being lifted off and polished to optical quality on both sides.

Laser-pierced hole arrays with lateral faces oriented along the $\langle 100\rangle$ direction were then fabricated on each substrate by the company Almax EasyLab using an Nd: YAG (yttrium aluminum garnet) laser, frequency doubled at $532 \mathrm{~nm}$. Confocal Laser Microscope (CLM) (Keyence VK9700) images of sample A1 after fabrication of the hole array are presented in Fig. 1(a).

To quantitatively evaluate the dislocation density, $10 \mathrm{~min}$ of plasma etching using a $\mathrm{H}_{2} / \mathrm{O}_{2}(98 \% / 2 \%)$ gas mixture ${ }^{37,38}$ was carried out. This aims at revealing dislocations in the form of inverted pyramidal shape square etch-pits (EPs), ${ }^{39}$ which are related to preferential etching at dislocations outcropping the surface. We also note that this plasma treatment helps removing any graphitic residues left by the laser process. A full map of EP distribution was then established by acquiring $2 \mathrm{D}$ images using the CLM. Three randomly selected $100 \times 100 \mu \mathrm{m}^{2}$ areas on the surface of the sample were investigated, and an average value was then deduced. The efficiency of our growth strategy was finally evaluated by comparing the dislocation density and distribution on the different areas (above the holes and between the holes) after the overgrowth.

The EP density was measured on both sides (presumably the growth side and the diamond/iridium nucleation side) of the heteroepitaxial substrate [Fig. 1(b)], leading to a similar value of $8 \times 10^{7} \mathrm{~cm}^{-2}$, in good agreement with the typical value reported by the supplier. ${ }^{14,23}$

Typical Raman spectra also acquired on both sides of the heteroepitaxial substrate are given in Fig. 1(c). In this case, a slight difference
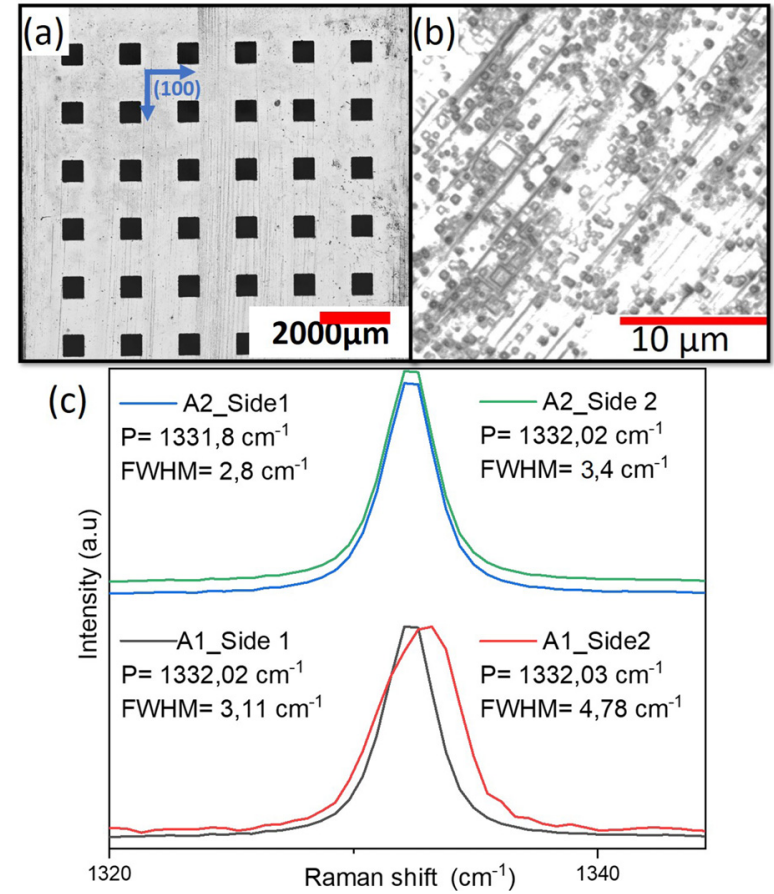

FIG. 1. (a) CLM image of the $500 \times 500 \mu \mathrm{m}^{2}\langle 100\rangle$ laser-pierced hole array realized on sample A1. (b) CLM image of the heteroepitaxial substrate surface after $\mathrm{H}_{2}$ l $\mathrm{O}_{2}$ plasma etching; the etch pits appear as black squares. (c) Diamond Raman peaks measured with a $473 \mathrm{~nm}$ laser on both sides of the substrates A1 and A2 (presumably the growth side and the diamond/iridium nucleation side).

in crystalline quality was found. Indeed, the corresponding Full Width at Half Maximum (FWHM) of the diamond peak for side 1 was narrower than that on side $2\left(3.11 \mathrm{~cm}^{-1}\right.$ vs $\left.4.78 \mathrm{~cm}^{-1}\right)$. This is possibly related to the growth direction of the sample. In fact, Stehl et al. ${ }^{22}$ showed that crystalline quality improves with the layer thickness. This would indicate that side 1 is the growth (i.e., thickened) side, while side 2 is presumably the diamond/iridium nucleation side. To be in optimal conditions, we selected the side with the lowest FWHM to perform the overgrowth step. A thick diamond layer was then deposited on samples A1 and A2 using a home-made CVD reactor under previously optimized growth conditions as reported in Table I.

After $140 \mathrm{~h}$ of growth, a $600-\mu \mathrm{m}$-thick layer of CVD diamond was obtained on A1. The hole array fully disappeared with the square holes progressively reducing in size, indicating that growth proceeded along $\langle 100\rangle$ directions. This corresponds to a normal growth rate

TABLE I. Growth conditions used for the overgrowth step.

\begin{tabular}{lcc}
\hline \hline Sample & A1 & A2 \\
\hline Pressure (mbar)/MW power $(\mathrm{W})$ & $200 / 3000$ & $200 / 3000$ \\
$\mathrm{CH}_{4} \%$ & 5 & 4 \\
Temperature $\left({ }^{\circ} \mathrm{C}\right)$ & 860 & 860 \\
Duration $(\mathrm{h})$ & 140 & 68 \\
Thickness $(\mu \mathrm{m})$ & 600 & 300 \\
\hline \hline
\end{tabular}


$\left(G r_{N}\right)$ of $4.3 \mu \mathrm{m} / \mathrm{h}$. The hole array was filled up after $113 \mathrm{~h}$, and the lateral growth rate $\left(G r_{l a t}\right)$ was then estimated to be $2.5 \mu \mathrm{m} / \mathrm{h}$. The growth rate ratio is calculated according to the below formula:

$$
\frac{G r_{l a t}}{G r_{N}}=\frac{\frac{l / 2}{t_{f}}}{\frac{e}{t_{g}}},
$$

with $l$ being the hole's length $(500 \mu \mathrm{m}), t_{f}$ the time needed to fill up the holes, $e$ the thickness of the grown layer, and $t_{g}$ the growth time. We obtain a ratio of 0.51 .

The surface morphology [cf. Figs. 2(b) and 2(c)] is smooth as for homoepitaxial diamond films with a comparable thickness. The FWHM of the diamond Raman peak is $2.24 \mathrm{~cm}^{-1}$ on the area above the holes (where lateral growth occurred) and $2.3 \mathrm{~cm}^{-1}$ outside the hole area. These values are close to those measured for high-quality homoepitaxial single crystalline diamond ${ }^{40}$ and already suggest a significant improvement as compared to the initial heteroepitaxial

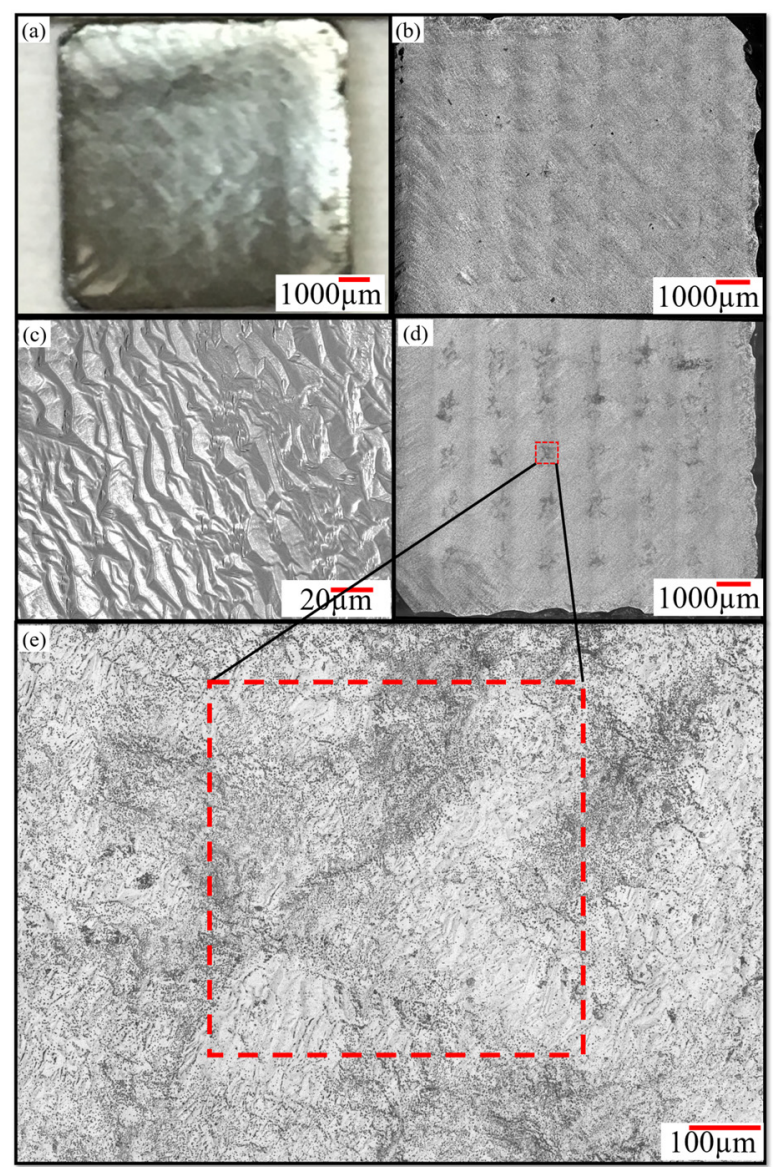

FIG. 2. (a) Optical and (b) and (c) CLM images of sample A1 after a $600 \mu \mathrm{m}$ overgrown diamond layer leading to a complete disappearance of the hole array. (d) and (e) CLM images after plasma etching to reveal the dislocation pattern. The initial position of the hole array is indicated by a red dashed square. The etch pits appear as dark dots in these images. substrate. We attribute this improvement to the thickening of the film under well-adapted growth conditions and high purity.

$\mathrm{H}_{2} / \mathrm{O}_{2}$ plasma etching was carried out to reveal EP, but, as presented in Figs. 2(d) and 2(e), no specific difference between the area above and between the holes is evidenced, suggesting that dislocation density remained similar over the entire sample or even slightly higher in the laterally grown regions. Indeed, we estimated the EP density to be $4.5 \times 10^{7} \mathrm{~cm}^{-2}$ between the holes and $6 \times 10^{7} \mathrm{~cm}^{-2}$ in the laterally grown areas (above the holes). Thus, in contrast to our expectation, no reduction in dislocation density was observed on this sample as compared to the initial substrate. Nevertheless, in these growth conditions, we should emphasize that unlike in the previous work on single crystal growth over a pierced HPHT single crystal substrate, ${ }^{36}$ the lateral to normal growth rate ratio $\left(\mathrm{Gr}_{\text {lat }} / \mathrm{Gr}_{\mathrm{N}}\right)$ was inferior to 1 . With such a small enlargement factor, we expect that the force exerted to bend dislocations toward the edges would not be high enough to prevent their vertical propagation along the $\langle 001\rangle$ direction rather than in the lateral direction in order to minimize their energy. ${ }^{41} \mathrm{We}$, thus, repeated the overgrowth under different growth conditions, leading to an increased $\mathrm{Gr}_{\text {lat }} / \mathrm{Gr}_{\mathrm{N}}$ ratio.

To do so, we overgrew sample A2 with a methane percentage of $4 \%$ instead of $5 \%$ in the gas phase, which is well known to strongly affect the growth rate along the different crystallographic directions. ${ }^{42}$ In particular, the growth rate in the $\langle 100\rangle$ direction is expected to decrease, thus inhibiting the growth of competitive faces and allowing a faster filling of the hole. The deposition duration was $68 \mathrm{~h}$ corresponding to a $300-\mu$ m-thick layer (i.e., a normal growth rate of $4.4 \mu \mathrm{m} / \mathrm{h}$ ), and the hole arrays were filled up after $43 \mathrm{~h}$, which corresponds to a lateral growth rate of $5.7 \mu \mathrm{m} / \mathrm{h}$. Figures 3(a)-3(c) confirm the expected improvement in terms of lateral growth. The $\mathrm{Gr}_{\text {lat }} / \mathrm{Gr}_{\mathrm{N}}$ ratio with this improved set of parameters was, thus, estimated to be 1.35. In addition, the hole array could be filled up in a much shorter time. The narrow window of operating conditions should be highlighted here since such a small variation in the methane concentration was able to drastically change the enlargement of the hole.

In contrast to the first sample, after $\mathrm{H}_{2} / \mathrm{O}_{2}$ plasma etching [cf. Figs. 3(d) and 3(e)], a significant difference in EP density between the areas above and between the holes was evidenced. A value of only $6 \times 10^{5} \mathrm{~cm}^{-2}$ was estimated locally in the laterally grown region (i.e., above the holes), which is the lowest reported so far on a heteroepitaxial diamond film. A dislocation density of $5 \times 10^{6} \mathrm{~cm}^{-2}$ was also measured outside the holes' region. If we normalize to the entire surface of the sample, we reach an average density of $4.6 \times 10^{6} \mathrm{~cm}^{-2}$, which is an order of magnitude better than the initial substrate before overgrowth but only moderately improved with respect to an untreated region. In fact, the surface covered by the holes currently represents only a modest $10 \%$ of the total area. By repeating the process with holes pierced in complementary areas, this averaged dislocation density value could be further improved. Moreover, we should emphasize that electronic devices fabricated on this large diamond platform could benefit from a lower dislocation density by being preferentially placed over the treated areas.

To further elucidate the growth mechanisms on the two overgrown samples, a thin cross-sectional slice was laser cut parallel to the $\langle 100\rangle$ lateral face in the center of a hole line and polished. The slices were then observed using a DiamondView ${ }^{\mathrm{TM}}$ that uses shortwavelength UV-light to excite fluorescence of the crystal (cf. Fig. 4). 


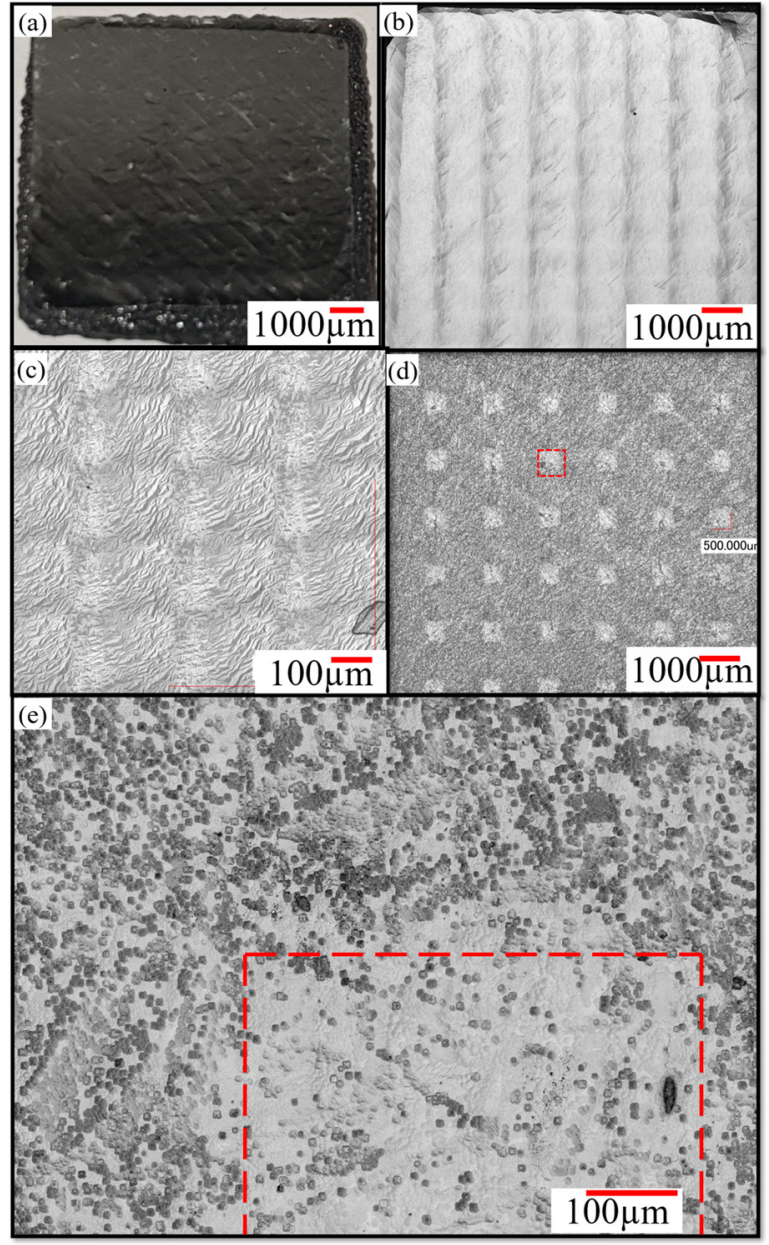

FIG. 3. (a) Optical and (b) and (c) CLM images of sample A2 after the $224 \mu \mathrm{m}$ overgrown layer. (d) and (e) CLM images after plasma etching to reveal the dislocation pattern. The initial position of the hole array is indicated by a red dashed square. The etch pits appear as dark dots in these images.

On the PL image, the initial substrate exhibits a bright red color that masks any other possible luminescence. It is indicative of the presence of nitrogen-vacancy (NV) centers incorporated from nitrogen addition that was presumably used during growth by the supplier. On the contrary, the CVD overgrown films do not show the presence of impurities, but blue luminescence related to stress (A band). Interestingly, by comparing the cross sections of $\mathrm{A} 1$ and $\mathrm{A} 2$, we confirm that, when the methane percentage is reduced, the lateral growth rate is increased, leading to sharp holes with smaller aspect ratios. This type of geometry is favorable to the bending of dislocations horizontally so that they will end on the free surfaces of the disappearing holes as schematically shown in Figs. 4(c) and 4(d). This strongly supports the observed reduction in dislocation density in the second case scenario. In addition, hole disappearance can be obtained in a much shorter growth time.

In summary, in this study, a key growth strategy was developed to reduce dislocation densities on commercial heteroepitaxial diamond substrates using $\langle 100\rangle$ laser-pierced hole arrays. It was shown that the

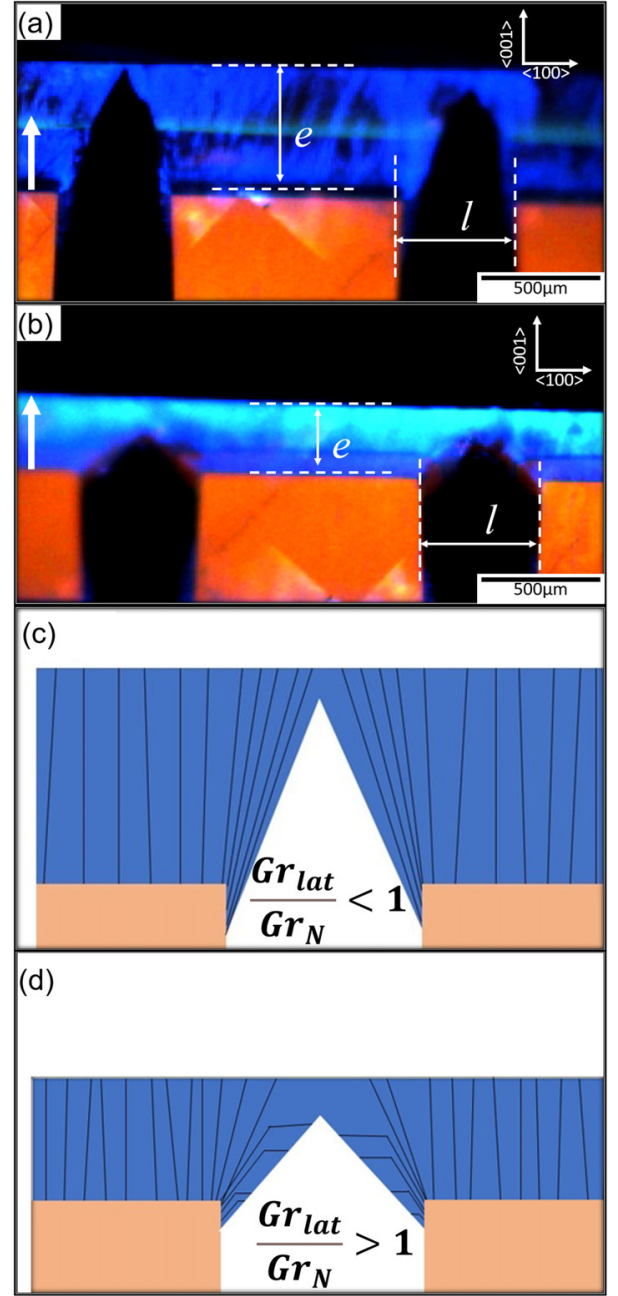

FIG. 4. (a) and (b) DiamondView photoluminescence UV images of cross sections cut from samples A1 and A2. In both images, the growth direction is indicated by a white arrow. The hole's length (I) and the thickness (e) of the grown layers are also indicated. Schematics illustrating the dislocation propagation in the overgrown layer in both scenarios: (c) sample A1 grown with $5 \% \mathrm{CH}_{4}\left(\frac{G r_{\text {lat }}}{G r_{N}}<1\right)$ and (d) sample A2 grown with $4 \% \mathrm{CH}_{4}\left(\frac{G r_{l a t}}{G r_{N}}>1\right)$.

lateral to normal growth rate ratio is key to limit the dislocation density by controlling their propagation direction. It relies on fine-tuning the hole's aspect ratio during growth so that dislocations are bent and can no longer propagate vertically toward the surface. We produced heteroepitaxial diamond films with a density as low as $6 \times 10^{5} \mathrm{~cm}^{-2}$ locally, in the region where lateral growth occurred, which is the lowest reported so far. This growth strategy, as long as the $\mathrm{Gr}_{\mathrm{lat}} / \mathrm{Gr}_{\mathrm{N}}$ ratio is greater than 1, paves the way for the production of large CVD diamond substrates having crystalline quality close to conventional $\mathrm{mm}^{2}$ synthetic diamonds. By extending this technique and applying additional and complementary hole arrays, one can expect producing heteroepitaxial diamonds with unprecedented crystalline quality, which could serve as large-area wafers for power electronics. A multistep process with holes pierced in different regions in each step can be 
implemented to improve the ratio of the surface area treated to the total surface area of the samples and further decrease the average dislocation density.

This work was financially supported by ANR (Agence Nationale de la Recherche) and DGA (Direction Générale de l'Armement) through National Project DIAMWAFEL No. ANR15-CE08-0034-03. ANR and CGI (Commissariat Générale à l'Investissement) are also gratefully acknowledged for their financial support through Labex SEAM (Science and Engineering for Advanced Materials and devices), Nos. ANR-10-LABX-0096 and ANR-18-IDEX-0001, and the Ile-de-France Region for their support within the framework of DIM SIRTEQ.

\section{DATA AVAILABILITY}

The data that support the findings of this study are available within this article.

\section{REFERENCES}

${ }^{1}$ S. Yamasaki, E. Gheeraert, and Y. Koide, "Doping and interface of homoepitaxial diamond for electronic applications," MRS Bull. 39(6), 499-503 (2014).

${ }^{2}$ S. Shikata, "Single crystal diamond wafers for high power electronics," Diamond Relat. Mater. 65, 168-175 (2016).

${ }^{3}$ A. Denisenko and E. Kohn, "Diamond power devices. Concepts and limits," Diamond Relat. Mater. 14(3-7), 491-498 (2005).

${ }^{4}$ M. Trejo, G. H. Jessen, K. D. Chabak, J. K. Gillespie, A. Crespo, M. Kossler, V. Trimble, D. Langley, E. R. Heller, B. Claflin et al., "Progress towards IIInitrides HEMTs on free-standing diamond substrates for thermal management," Phys. Status Solidi A 208(2), 439-444 (2011).

${ }^{5}$ L. Bäni, A. Alexopoulos, M. Artuso, F. Bachmair, M. Bartosik, J. Beacham, H. Beck, V. Bellini, V. Belyaev, B. Bentele et al., "Diamond detectors for high energy physics experiments,” J. Instrum. 13(01), C01029 (2018).

${ }^{6}$ H. Kagan, A. Alexopoulos, M. Artuso, F. Bachmair, L. Bäni, M. Bartosik, J. Beacham, H. Beck, V. Bellini, V. Belyaev et al., "Diamond detector technology, status and perspectives," Nucl. Instrum. Methods Phys. Res., Sect. A 924, 297-300 (2019).

${ }^{7}$ H. Yamada, A. Chayahara, Y. Mokuno, N. Tsubouchi, and S.-I. Shikata, "Uniform growth and repeatable fabrication of inch-sized wafers of a singlecrystal diamond," Diamond Relat. Mater. 33, 27-31 (2013).

${ }^{8}$ G. Shu, B. Dai, V. G. Ralchenko, A. A. Khomich, E. E. Ashkinazi, A. P. Bolshakov, S. N. Bokova-Sirosh, K. Liu, J. Zhao, J. Han et al., "Epitaxial growth of mosaic diamond: Mapping of stress and defects in crystal junction with a confocal Raman spectroscopy," J. Cryst. Growth 463, 19-26 (2017).

${ }^{9}$ H. Y. Shinya Ohmagari, N. Tsubouchi, H. Umezawa, A. Chayahara, A. Seki, F. Kawaii, H. Saitoh, and Y. Mokuno, "Schottky barrier diodes fabricated on diamond mosaic wafers: Dislocation reduction to mitigate the effect of coalescence boundaries," Appl. Phys. Lett. 114, 082104 (2019).

${ }^{10}$ Y. Ando, J. Kuwabara, K. Suzuki, and A. Sawabe, "Patterned growth of heteroepitaxial diamond," Diamond Relat. Mater. 13(11-12), 1975-1979 (2004).

${ }^{11}$ H. Aida, S.-W. Kim, K. Ikejiri, Y. Kawamata, K. Koyama, H. Kodama, and A. Sawabe, "Fabrication of freestanding heteroepitaxial diamond substrate via micropatterns and microneedles," Appl. Phys. Express 9(3), 035504 (2016).

${ }^{12}$ H. Aida, K. Ikejiri, S.-W. Kim, K. Koyama, Y. Kawamata, H. Kodama, and A. Sawabe, "Overgrowth of diamond layers on diamond microneedles: New concept for freestanding diamond substrate by heteroepitaxy," Diamond Relat. Mater. 66, 77-82 (2016).

${ }^{13}$ T. Yoshikawa, H. Kodama, S. Kono, K. Suzuki, and A. Sawabe, "Wafer bowing control of free-standing heteroepitaxial diamond (100) films grown on $\operatorname{Ir}(100)$ substrates via patterned nucleation growth," Thin Solid Films 594, 120-128 (2015).

${ }^{14}$ M. Schreck, S. Gsell, R. Brescia, and M. Fischer, "Ion bombardment induced buried lateral growth: The key mechanism for the synthesis of single crystal diamond wafers," Sci. Rep. 7, 44462 (2017).
${ }^{15}$ A. F. Sartori, M. Fischer, S. Gsell, and M. Schreck, "In situ boron doping during heteroepitaxial growth of diamond on Ir/YSZ/Si," Phys. Status Solidi A 209(9), $1643-1650$ (2012).

${ }^{16}$ M. Fischer, R. Brescia, S. Gsell, M. Schreck, T. Brugger, T. Greber, J. Osterwalder, and B. Stritzker, "Growth of twin-free heteroepitaxial diamond on Ir/YSZ/Si(111),” J. Appl. Phys. 104(12), 123531 (2008).

${ }^{17}$ M. Fischer, S. Gsell, M. Schreck, R. Brescia, and B. Stritzker, "Preparation of 4inch $\mathrm{Ir} / \mathrm{YSZ} / \mathrm{Si}(001)$ substrates for the large-area deposition of single-crystal diamond," Diamond Relat. Mater. 17(7-10), 1035-1038 (2008).

${ }^{18}$ K. H. Lee, S. Saada, J.-C. Arnault, R. Moalla, G. Saint-Girons, R. Bachelet, H. Bensalah, I. Stenger, J. Barjon, A. Tallaire et al., "Epitaxy of iridium on $\mathrm{SrTiO}_{3}$ / Si (001): A promising scalable substrate for diamond heteroepitaxy," Diamond Relat. Mater. 66, 67-76 (2016).

${ }^{19} \mathrm{~K}$. H. Lee, "Hétéroépitaxie de films de diamant sur $\mathrm{Ir} / \mathrm{SrTiO}_{3} / \mathrm{Si}(001)$ : une voie prometteuse pour l'élargissement des substrats," Ph.D. thesis (Université ParisSaclay, 2017).

${ }^{20}$ J. C. Arnault, K. H. Lee, J. Delchevalrie, J. Penuelas, L. Mehmel, O. Brinza, S. Temgoua, I. Stenger, J. Letellier, G. Saint-Girons et al., "Epitaxial diamond on $\mathrm{Ir} / \mathrm{SrTiO}_{3} / \mathrm{Si}(001)$ : From sequential material characterizations to fabrication of lateral Schottky diodes," Diamond Relat. Mater. 105, 107768 (2020).

${ }^{21}$ S. Gsell, T. Bauer, J. Goldfuß, M. Schreck, and B. Stritzker, “A route to diamond wafers by epitaxial deposition on silicon via iridium/yttria-stabilized zirconia buffer layers," Appl. Phys. Lett. 84(22), 4541-4543 (2004).

${ }^{22}$ C. Stehl, M. Fischer, S. Gsell, E. Berdermann, M. S. Rahman, M. Traeger, O. Klein, and M. Schreck, "Efficiency of dislocation density reduction during heteroepitaxial growth of diamond for detector applications," Appl. Phys. Lett. 103(15), 151905 (2013).

${ }^{23}$ M. Schreck, A. Schury, F. Hörmann, H. Roll, and B. Stritzker, "Mosaicity reduction during growth of heteroepitaxial diamond films on iridium buffer layers: Experimental results and numerical simulations," J. Appl. Phys. 91(2), 676-685 (2002).

${ }^{24}$ J. Achard, A. Tallaire, V. Mille, M. Naamoun, O. Brinza, A. Boussadi, L. William, and A. Gicquel, "Improvement of dislocation density in thick CVD single crystal diamond films by coupling $\mathrm{H}_{2} / \mathrm{O}_{2}$ plasma etching and chemomechanical or ICP treatment of HPHT substrates," Phys. Status Solidi A 211(10), 2264-2267 (2014).

${ }^{25}$ T. N. Tran Thi, J. Morse, D. Caliste, B. Fernandez, D. Eon, J. Hartwig, C. Barbay, C. Mer-Calfati, N. Tranchant, J. C. Arnault et al., "Synchrotron Bragg diffraction imaging characterization of synthetic diamond crystals for optical and electronic power device applications," J. Appl. Crystallogr. 50(Pt. 2), 561-569 (2017).

${ }^{26}$ R. C. Burns, A. I. Chumakov, S. H. Connell, D. Dube, H. P. Godfried, J. O. Hansen, J. Hartwig, J. Hoszowska, F. Masiello, L. Mkhonza et al., "HPHT growth and x-ray characterization of high-quality type IIa diamond," J. Phys. 21(36), 364224 (2009).

${ }^{27}$ A. Tallaire, V. Mille, O. Brinza, T. N. Tran Thi, J. M. Brom, Y. Loguinov, A. Katrusha, A. Koliadin, and J. Achard, "Thick CVD diamond films grown on high-quality type IIa HPHT diamond substrates from New Diamond Technology," Diamond Relat. Mater. 77, 146-152 (2017).

${ }^{28}$ Y. H. Tang and B. Golding, "Stress engineering of high-quality single crystal diamond by heteroepitaxial lateral overgrowth," Appl. Phys. Lett. 108(5), 052101 (2016).

${ }^{29}$ Y.-H. Tang, B. Bi, and B. Golding, "Diamond heteroepitaxial lateral overgrowth," Mater. Res. Soc. Symp. Proc. 1734, mrsf14-1734-r05-04 (2015).

${ }^{30}$ K. Ichikawa, K. Kurone, H. Kodama, K. Suzuki, and A. Sawabe, "High crystalline quality heteroepitaxial diamond using grid-patterned nucleation and growth on Ir," Diamond Relat. Mater. 94, 92-100 (2019).

${ }^{31}$ S. Ohmagari, H. Yamada, N. Tsubouchi, H. Umezawa, A. Chayahara, S. Tanaka, and Y. Mokuno, "Large reduction of threading dislocations in diamond by hot-filament chemical vapor deposition accompanying $\mathrm{W}$ incorporations," Appl. Phys. Lett. 113(3), 032108 (2018).

${ }^{32}$ S. Ohmagari, H. Yamada, N. Tsubouchi, H. Umezawa, A. Chayahara, Y. Mokuno, and D. Takeuchi, "Toward high-performance diamond electronics: Control and annihilation of dislocation propagation by metal-assisted termination," Phys. Status Solidi A 216(21), 1900498 (2019).

${ }^{33}$ K. Linthicum, T. Gehrke, D. Thomson, E. Carlson, P. Rajagopal, T. Smith, D. Batchelor, and R. Davis, "Pendeoepitaxy of gallium nitride thin films," Appl. Phys. Lett. 75(2), 196-198 (1999). 
${ }^{34}$ A. Usui, H. Sunakawa, A. Sakai, and A. Yamaguchi, "Thick GaN epitaxial growth with low dislocation density by hydride vapor phase epitaxy," Jpn. J. Appl. Phys., Part 2 36, L899 (1997).

${ }^{35}$ Springer Handbook of Crystal Growth, edited by G. Dhanaraj, K. Byrappa, V. Prasad, and M. Dudley (Springer-Verlag, Berlin/Heidelberg, Germany, 2010).

${ }^{36}$ A. Tallaire, O. Brinza, V. Mille, L. William, and J. Achard, "Reduction of dislocations in single crystal diamond by lateral growth over a macroscopic hole," Adv. Mater. 29, 1604823 (2017).

${ }^{37}$ A. Tallaire, T. Ouisse, A. Lantreibecq, R. Cours, M. Legros, H. Bensalah, J. Barjon, V. Mille, O. Brinza, and J. Achard, "Identification of dislocations in synthetic chemically vapor deposited diamond single crystals," Cryst. Growth Des. 16(5), 2741-2746 (2016).

${ }^{38}$ M. Naamoun, A. Tallaire, F. Silva, J. Achard, P. Doppelt, and A. Gicquel, "Etch-pit formation mechanism induced on HPHT and CVD diamond single crystals by $\mathrm{H}_{2} / \mathrm{O}_{2}$ plasma etching treatment," Phys. Status Solidi A 209(9), 1715-1720 (2012).
${ }^{39}$ J. Achard, F. Silva, O. Brinza, X. Bonnin, V. Mille, R. Issaoui, M. Kasu, and A. Gicquel, "Identification of etch-pit crystallographic faces induced on diamond surface by $\mathrm{H}_{2} / \mathrm{O}_{2}$ etching plasma treatment," Phys. Status Solidi A 206(9), 1949-1954 (2009).

${ }^{40}$ A. Tallaire, J. Achard, F. Silva, R. S. Sussmann, and A. Gicquel, "Homoepitaxial deposition of high-quality thick diamond films: Effect of growth parameters," Diamond Relat. Mater. 14(3-7), 249-254 (2005).

${ }^{41}$ P. Martineau, M. Gaukroger, R. Khan, and D. Evans, "Effect of steps on dislocations in CVD diamond grown on $\{001\}$ substrates," Phys. Status Solidi C 6(8), 1953-1957 (2009).

${ }^{42}$ O. Brinza, J. Achard, F. Silva, X. Bonnin, P. Barroy, K. D. Corte, and A. Gicquel, "Dependence of CVD diamond growth rate on substrate orientation as a function of process parameters in the high microwave power density regime," Phys. Status Solidi A 205(9), 2114-2120 (2008). 